\title{
A liderança carismática exercida pelas novas líderes pentecostais femininas de Nova Iguaçu: um diálogo com Charles Lindholm
}

\author{
Janine Targino da Silva*
}

\begin{abstract}
Resumo: Seguindo as elaborações teóricas weberianas sobre o carisma, Charles Lindholm desenvolve em seu livro "Carisma: êxtase e perda de identidade na veneração ao líder" um estudo detalhado sobre aquilo que classifica como liderança carismática. Através da análise dos perfis de personalidades polêmicas do século XX, tais como Adolf Hitler, Charles Mansone Jim Jones, Lindholm descreve com bastante propriedade o que vem a ser o carisma e os reflexos do mesmo nas relações entre líderes e liderados. Da mesma forma que Max Weber, este autor trabalha com a idéia de que o carisma trata-se de um conjunto de qualidades extracotidianas em virtude das quais são atribuídos a uma pessoa poderes ou atributos sobrenaturais, sobre-humanos ou extraordinários. Além disso, Lindholm conclui que o carisma torna a pessoa capaz de envolver emocionalmente outros indivíduos. Para Lindholm, o indivíduo carismático geralmente possui a capacidade de atrair discípulos, uma vez que o carisma confere magnetismo ao líder. Em diálogo direto com Lindholm, esta comunicação pretende analisar o surgimento de novas lideranças pentecostais femininas em Nova Iguaçu, município integrante da Baixada Fluminense. Nossa principal hipótese é de que, da mesma forma que a liderança carismática retratada por Lindholm, estas mulheres exercem a liderança religiosa pautadas no envolvimento emocional suscitado entre elas e seus seguidores. Os dados analisados nesta comunicação são provenientes de pesquisa de campo e de entrevistas feitas com as líderes e seus seguidores.
\end{abstract}

Palavras-Chave: Carisma, Liderança Feminina, Liderança Religiosa, Novos Movimentos Pentecostais

\begin{abstract}
Following the weberians theoretical elaborations on charisma, Charles Lindholm develops in his book "Charisma: ecstasy and loss of identity in the veneration to the leader" a detailed study on what he classifies as charismatic leadership. Through the analysis on the profiles of controverted personalities of XXth century, such as Adolf Hitler, Charles Manson and Jim Jones, Lindholm describes with property what defines charisma and its consequences in the relations between led and leaders. As Max Weber, this author works on the idea that charisma is a set of extradaily qualities by virtue of which a person is set apart from ordinary people and treated as endowed with supernatural, superhuman, or at least specifically exceptional powers or qualities. Moreover, Lindholm concludes that the charismatic one becomes a competent person to involve emotionally other individuals. For Lindholm, the charismatic individual generally possesses the capacity to attract disciples, once the charisma confers magnetism to the leader. In direct dialogue with Lindholm, this communication intends
\end{abstract}

\footnotetext{
* Janine Targino da Silva é mestranda do Programa de Pós-Graduação em Ciências Sociais da Universidade do Estado do Rio de Janeiro (PPCIS-UERJ). Esta pesquisa foi realizada com o apoio da Capes.
}

INTRATEXTOS, Rio de Janeiro, Número Especial 01, pp. 151-168, 2010. 
to analyze the sprouting of new feminine pentecostal leaderships in Nova Iguaçu, in Rio de Janeiro state. Our main hypothesis is that, in the same way that Lindholm portraied the charismatic leadership, these women exert the religious leadership based on exciting emotional involvement with their followers. The data analyzed in this communication are proceeded from field research and interviews made with the leaders and its followers.

Keywords: Charisma, Feminine Leadership, Religious Leadership, New Pentecostals Movements.

\section{Introdução}

Seguindo as elaborações teóricas weberianas sobre o carisma, Charles Lindholm desenvolve em seu livro "Carisma: êxtase e perda de identidade na veneração ao líder" um estudo detalhado sobre aquilo que classifica como liderança carismática. Através da análise dos perfis de personalidades polêmicas do século XX, tais como Adolf Hitler, Charles Manson e Jim Jones, Lindholm descreve com bastante propriedade o que vem a ser o carisma e os reflexos do mesmo nas relações entre líderes e liderados. Assim como Max Weber, este autor trabalha com a idéia de que o carisma trata-se de um conjunto de qualidades extracotidianas, em virtude das quais são atribuídos a uma pessoa poderes ou atributos sobrenaturais, sobre-humanos ou extraordinários. Contudo, Lindholm vai além e nos diz que, em última análise, o carisma é vivenciado com base em sensações de êxtase e de perda de identidade dentro de um grupo que se organiza em torno de uma figura carismática que, algumas vezes, pode ser encarado como um deus vivo (LINDHOLM, 1993: 9). Este autor também nos indica que o carisma torna o líder capaz de envolver emocionalmente outros indivíduos. Para Lindholm, o indivíduo carismático geralmente possui a capacidade de atrair discípulos, uma vez que o carisma confere magnetismo a quem o possui.

Em seu prefácio à edição brasileira de seu livro, Lindholm lança uma questão: qual interesse os leitores brasileiros teriam por uma pesquisa dedicada ao carisma? Por conseguinte, o autor conclui que os movimentos carismáticos insurgem quando as pessoas sentem-se marginalizadas e deixadas à própria sorte, sobretudo quando o ambiente apresenta condições adversas à sobrevivência dos indivíduos. Fatores como a desintegração progressiva do tecido social tornariam as pessoas mais propensas a abrirem mão de sua identidade, muitas vezes já bastante prejudicada, em prol de uma experiência de grupo na qual se pode vivenciar o transcendente. Tendo em vista que o 
Brasil, com sua ampla desigualdade social, promoveu ao longo das últimas décadas um processo contínuo de desvalorização e marginalização dos indivíduos das camadas sociais mais baixas, a discussão acerca da liderança carismática ganha relevo e importância para a sociologia brasileira. Sobretudo em áreas onde os índices de desenvolvimento humano são inexpressivos, como, por exemplo, a Baixada Fluminense, somos levados a acreditar que o estudo dos movimentos que podem ser caracterizados como carismáticos, sejam eles religiosos ou não, é de extrema importância. Além disso, estudos voltados mais especificamente aos movimentos religiosos que possuem traços carismáticos também colaboram sobremaneira para o enriquecimento do campo das pesquisas científicas produzidas sobre o fenômeno religioso de maneira geral.

Em diálogo direto com Lindholm, esta comunicação pretende analisar o insurgimento de novas lideranças pentecostais femininas em Nova Iguaçu, município integrante da Baixada Fluminense ${ }^{1}$. Nossa principal hipótese é que, da mesma forma que a liderança carismática retratada por Lindholm, estas mulheres exercem a liderança religiosa pautadas no envolvimento emocional suscitado entre elas e seus seguidores. Não obstante, outras características, também apontadas como componentes do carisma, serão analisadas no sentido de melhor expor a configuração da liderança exercida pelas novas líderes. Procuramos, nesta sucinta exposição, colaborar para a diminuição do déficit de informações sobre mulheres carismáticas que atuam como lideranças nas mais variadas esferas sociais. Segundo o próprio Lindholm, seu estudo em torno da liderança carismática está essencialmente orientado pela perspectiva masculina, uma vez que os líderes masculinos possuem maior notoriedade nos relatos etnográficos que lhe serviram como fonte de dados para sua pesquisa. Dessa forma, esperamos que as informações aqui apresentadas atuem no sentido de estimular não apenas o estudo da liderança feminina exercida no âmbito pentecostal, mas, também, a realização de pesquisas acerca da liderança feminina $e$ carismática nas mais diversas esferas sociais.

Os dados apresentados e analisados a seguir nesta comunicação são provenientes da aplicação de duas técnicas de pesquisa qualitativa. A primeira delas trata-se de

\footnotetext{
${ }^{1}$ A baixada Fluminense trata-se de uma área periférica do Rio de Janeiro constituída pelos municípios de Belford Roxo, Duque de Caxias, Mesquita, Nilópolis, Nova Iguaçu, Queimados e São João de Meriti. Com baixos indicadores de desenvolvimento humano, esta região caracteriza-se pela ineficácia da assistência do poder público á população em geral e pelos altos índices de criminalidade/violência e marginalização.
}

INTRATEXTOS, Rio de Janeiro, Número Especial 01, pp. 151-168, 2010. 
pesquisa de campo feita em onze igrejas pentecostais fundadas por mulheres no município de Nova Iguaçu ${ }^{2}$. A segunda fonte de dados corresponde às entrevistas feitas com as líderes das igrejas pesquisadas e alguns de seus seguidores. Tanto a pesquisa de campo quanto as entrevistas foram realizadas no decorrer do segundo semestre de 2008 e do primeiro semestre do ano corrente.

\section{2- Quadro da participação feminina no meio pentecostal e neopentecostal - anseios de liderança}

Segundo os dados da pesquisa "Economia das Religiões" realizada pelo Centro de Políticas Sociais da Fundação Getúlio Vargas ${ }^{3}$, 19,34\% das mulheres que compõem a população brasileira é convertida às igrejas evangélicas ${ }^{4}$, enquanto apenas $16,37 \%$ dos homens brasileiros declaram-se evangélicos. Esta desproporção entre o percentual de homens e mulheres seguidores de igrejas evangélicas está igualmente presente no grupo das igrejas pentecostais e neopentecostais ${ }^{5}$. Ainda segundo os dados da pesquisa "Economia das Religiões", no âmbito nacional 11,44\% dos homens designam-se como pentecostais, enquanto $13,51 \%$ das mulheres brasileiras são convertidas ao pentecostalismo. Também no estado do Rio de Janeiro podemos ver esta desproporção.

\footnotetext{
${ }^{2}$ Dois critérios foram decisivos na etapa de seleção das igrejas que serviriam de campo para a pesquisa. Em primeiro lugar, como um quesito central que movimenta toda a pesquisa em desenvolvimento, todas as igrejas selecionadas para a observação foram fundadas por mulheres convertidas ao pentecostalismo em algum dos bairros do município de Nova Iguaçu. Em segundo lugar, optamos por trabalhar com igrejas fundadas por líderes que não possuem nenhum tipo de relacionamento entre si. Este critério surgiu da necessidade de evitar constrangimentos e inconveniências já que, durante a etapa de escolha das igrejas que seriam observadas na pesquisa de campo, percebi que algumas das líderes estabeleciam uma espécie de competição direta entre si no que diz respeito ao séqüito e outras questões. Sendo assim, ao optar por trabalhar com igrejas comandadas por mulheres que não sabem da existência uma das outras, evitam-se situações do tipo "ou ela ou eu", que já se configuravam durante a etapa prévia de seleção das igrejas.

${ }^{3}$ A pesquisa "Economia das Religiões" realizada pelo Centro de Políticas Sociais da Fundação Getulio Vargas (CPS/IBRE/FGV) dá continuidade à linha de pesquisa lançada em abril de 2005, intitulada "Retratos da Religião Brasileira". O banco de dados da pesquisa está disponível na página da internet www4.fgv.br/cps/simulador/site_religioes2.

4 O termo "evangélico" é usado para designar o grupo formado pelas igrejas protestantes históricas, pentecostais e neopentecostais, especialmente no contexto religioso da América Latina.

${ }^{5}$ De acordo com Mariano (2004), o pentecostalismo se distingue do protestantismo histórico por acreditar na contemporaneidade dos dons do Espírito Santo, com ênfase nos dons de línguas e cura, e por sustentar a crença em preceitos e práticas do cristianismo primitivo, tais como a expulsão de demônios e a realização de milagres.
}

INTRATEXTOS, Rio de Janeiro, Número Especial 01, pp. 151-168, 2010. 
Nas fileiras das igrejas pentecostais e neopentecostais estão 15,99\% das mulheres residentes no estado, contra apenas $12,43 \%$ dos homens fluminenses ${ }^{6}$.

Vários seriam os fatores que explicariam esta desigualdade da participação de homens e mulheres no meio evangélico. Segundo Machado \& Mariz (1997) as igrejas pentecostais e neopentecostais possuem uma proposta religiosa que se torna bastante atrativa às mulheres. Para estas autoras, o pentecostalismo e o neopentecostalismo constituem uma vertente religiosa que propicia a criação de espaços alternativos para a discussão de problemas familiares, ao mesmo tempo em que possibilita a construção de redes sociais que ajudam as mulheres a recuperarem a auto-estima, a diferenciarem-se de seus familiares e a entrarem no mercado de trabalho. Autores como Fry \& Howe (1975) também destacam que o pentecostalismo, assim como a umbanda e as religiões afro espíritas em geral, possui a capacidade de atrair os indivíduos que passam por problemas e/ou situações cotidianas de opressão. Ou seja, de acordo com Fry \& Howe, o pentecostalismo exerce uma atração especial sobre negros, pobres, doentes, idosos, desempregados e mulheres. Além disso, como nos indica Birman (1996), não devemos nos esquecer que as igrejas pentecostais tratam fundamentalmente das aflições humanas, e tais assuntos, geralmente, estão vinculados à esfera doméstica. Em função disso, cria-se uma situação onde a mulher passa a exercer o importante papel de mediadora na relação com o sagrado dentro de suas famílias (BIRMAN, Ibidem). Dessa maneira, pode-se dizer que estas novas possibilidades abertas pelas igrejas pentecostais e neopentecostais às mulheres são as grandes responsáveis pela maior presença feminina nas fileiras destas instituições.

Contudo, ainda que as mulheres representem a maior parte do séqüito das igrejas evangélicas, a parcela feminina é impedida de exercer o pastorado na maioria das congregações. Em uma perspectiva histórica, vemos que apenas as igrejas históricas (metodistas, luteranas e anglicanas), duas igrejas pentecostais (Exército da Salvação e Igreja do Evangelho Quadrangular) e, posteriormente, a Presbiteriana Unida, não vetavam o pastorado feminino (SANTOS, 2002). Este quadro começa a mudar consideravelmente na década de 1980, pois, neste período, inicia-se o crescimento das vertentes pentecostal e neopentecostal e, simultaneamente a tal crescimento, a abertura

\footnotetext{
${ }^{6}$ Dados da pesquisa "Economia das Religiões".
} 
para o surgimento de novas lideranças religiosas femininas no âmbito das igrejas evangélicas (SANTOS, Ibidem).

Os anseios femininos pelo exercício de funções de liderança dentro das igrejas provocam tensões. Mesmo nas igrejas que permitem o pastorado feminino, a hierarquia permanece fortemente marcada pela figura masculina, e isso cria vários pontos de divergências entre as líderes e os representantes da parcela masculina. Somado a isso, temos também os descontentamentos de mulheres seguidoras de igrejas que sob nenhum aspecto aceitam o pastorado feminino. Em vários casos, estas mulheres sentem o “chamado" para o pastorado, mas não encontram meios para viabilizá-lo nas igrejas que seguem. Dessa forma, por um lado temos a insatisfação vivida por líderes estabelecidas em igrejas que perpetuam o modelo de hierarquia pautado no elemento masculino. Por outro, temos a contrariedade com a qual se deparam mulheres que, mesmo cientes de sua capacidade de liderança, são impedidas de chegarem ao pastorado.

Como desdobramento desta conjunção de fatores insurge a criação de igrejas fundadas por mulheres dissidentes de grandes igrejas pentecostais e neopentecostais. Este fenômeno bastante peculiar tem sido observado em toda Baixada Fluminense, e particularmente constatado em Nova Iguaçu, o maior município da região. Segundo Jacob et alli (2006), os percentuais de fiéis pentecostais no município de Nova Iguaçu giram em torno de $30 \%$, superando o percentual de evangélicos do estado do Rio de Janeiro, que, de acordo com o último Censo Demográfico, é de 21,18\%. Tendo em vista a amplitude dos percentuais referentes ao conjunto evangélico iguaçuano, podemos sugerir que esta região possui atributos importantes para a viabilização do fenômeno religioso em questão.

Impulsionadas pela vontade de viver sua "fé" de um modo alternativo, sem estarem submissas a uma hierarquia que, na maioria das vezes, não delega cargos de liderança ao séquiito feminino, estas mulheres rompem com as congregações pentecostais e neopentecostais das quais eram seguidoras e fundam pequenas igrejas em espaços adaptados. Nestas igrejas, as "autoproclamadas" bispas e pastoras ocupam o lugar central para a tomada de todas as decisões em suas igrejas, enquanto aos homens é reservada uma posição que se caracteriza pela obediência e submissão às líderes. Os cultos ministrados pelas líderes têm nas orações de cura e revelações ${ }^{7}$ seus principais

\footnotetext{
${ }^{7}$ De acordo com as elaborações cosmológicas nativas, pode-se definir revelação como uma mensagem enviada às líderes por Deus ou por um anjo para que seja repassada a determinado indivíduo presente no
} 
atrativos. Já a clientela destas igrejas, que gira em torno de 30 pessoas, é formada majoritariamente por mulheres com um amplo histórico de participações em outras denominações pentecostais e neopentecostais, das quais não se desvinculam para aderirem a estes grupos.

Antes de prosseguirmos com a exposição e análise do fenômeno em tela é necessário enquadrá-lo no contexto mais amplo das transformações pelas quais passam as identidades religiosas na contemporaneidade. Neste sentido, a análise feita por Hervieu-Léger (2008) pode ser usada para demonstrar que a atitude das novas líderes ao percorrerem uma via alternativa, através do pastorado feminino, para vivenciarem sua religiosidade pentecostal condiz com as tendências modernas que orientam o comportamento dos atores no âmbito religioso. De acordo com esta autora, o crente moderno busca validar, de várias maneiras, seu "direito à bricolagem" e de escolher suas crenças. A busca pessoal pela verdade ganha relevo neste contexto, já que mesmo aqueles indivíduos integrados em uma confissão particular irão elaborar suas identidades sócio-religiosas pautados nos recursos simbólicos que dispõem e que atravessam suas vidas (HERVIEU-LÉGER, Ibidem). Este é o caso das novas líderes observadas por esta pesquisa que, por não encontrarem respaldo para seus anseios de liderança nas igrejas às quais eram convertidas, acessam outras vias para que possam exercer o pastorado e, simultaneamente, re-elaborarem suas identidades religiosas no meio pentecostal.

\section{3- Perfil geral das novas líderes pentecostais de Nova Iguaçu}

Para que seja possível um melhor entendimento sobre esta exigência de maior poder eclesiástico manifestada pelas novas líderes, a elaboração de um perfil geral das mesmas pode ser bastante revelador. Sem deixar de lado o fato de que cada um dos casos possui inúmeras singularidades que inviabilizam quaisquer tipos de

culto com o intuito de torná-lo ciente das verdadeiras razões de seus problemas ou comunicar-lhe alguma benção iminente. A mensagem a ser transmitida ao fiel é repassada ao público como um todo, e só após todos tomarem conhecimento da mensagem é que seu destinatário se identifica frente aos presentes. A identificação do destinatário da mensagem pode ser um ato voluntário do mesmo, ou pode ser feita pela própria pastora que o aponta dentre os fiéis presentes. Após o conhecimento do indivíduo ao qual se destina a revelação, espera-se que o mesmo dirija-se até o altar e aceite a oração feita pela pastora para que o "mal revelado" seja totalmente neutralizado, ou para que a "benção revelada" seja verdadeiramente concretizada.

INTRATEXTOS, Rio de Janeiro, Número Especial 01, pp. 151-168, 2010. 
generalizações, o cruzamento das características que estas mulheres têm em comum pode nos servir de norteador na construção de uma análise consistente sobre esta nova configuração de liderança religiosa.

A primeira característica que pode ser apontada como comum entre as líderes entrevistadas é a localização das mesmas na estrutura sócio-econômica. Todas elas são oriundas da classe popular e apresentam carências de várias ordens. É corriqueiro, e ao mesmo tempo perturbador, encontrar entre estas líderes mulheres sem escolaridade suficiente para ocupar um posto de trabalho que exija um grau mínimo de formação escolar. Inevitavelmente, isso leva estas mulheres a trabalharem em funções mais subalternas ou, simplesmente, levam-nas a optarem por viver apenas dos rendimentos conseguidos através do que é ofertado às suas igrejas. Somente uma das pastoras entrevistas apresentava grau superior completo, com formação em psicologia, mas ainda assim não exercia a função para qual havia se formado.

Tendo em vista o fato de que estas líderes encontram-se a margem do usufruto das possibilidades abertas ás mulheres com vários anos de escolaridade, o exercício da liderança dentro da religião pode significar para estas mulheres a busca por um poder possível de ser alcançado, ainda que no plano simbólico-religioso. Ser uma líder religiosa, em vários aspectos, atende a anseios que vão desde a vontade de obter reconhecimento pela posse de um traço singular que as diferencie dos demais em sua comunidade, até o desejo de efetivamente ocuparem um cargo de relevância dentro da igreja.

Outra característica recorrente entre as novas líderes é a forma como se configuram suas famílias. Entre as onze líderes entrevistadas apenas três delas são casadas, sendo as demais divorciadas ou viúvas. Este dado torna-se bastante relevante se pensarmos no fato de que no âmbito pentecostal as mulheres são orientadas a acompanharem e obedecerem seus maridos, ainda que estes não sejam crentes (MACHADO \& MARIZ, 1996). Embora a mulher pentecostal possua um alto grau de envolvimento com seus compromissos religiosos, sua participação na igreja jamais deve ser uma prioridade maior que seus deveres para com seus filhos e marido. Há mesmo nas igrejas pentecostais o cuidado para "evitar que as mulheres levem longe demais sua independência em relação aos seus cônjuges" (MACHADO \& MARIZ, 1996: 13). Dessa forma, quando se vêem na condição de viúvas ou divorciadas, as mulheres encontram a possibilidade de vivenciar a fé pentecostal sem estarem necessariamente 
submetidas a um poder patriarcal. A viuvez e o divórcio, para estas novas líderes, podem significar o momento no qual se conquista maior liberdade para se dedicar integralmente às práticas religiosas através do exercício do pastorado, sem o empecilho de terem que obrigatoriamente dividirem-se entre as atividades domésticas e a igreja.

O dado de que grande parte dessas novas líderes são viúvas ou divorciadas aponta para mais uma característica de suma importância: estas mulheres também ocupam a função de "chefes de família". Exceto pelas líderes casadas, as demais entrevistadas cuidam sozinhas de suas famílias, e em alguns casos são a única fonte de renda em suas casas. Dessa maneira, antes mesmo de serem líderes religiosas, estas mulheres também constituem lideranças dentro de suas famílias, cuidando sozinhas de seus filhos e, muitas vezes, estendendo este cuidado aos seus netos.

Do mesmo modo, a atuação das novas líderes nos locais em que habitam possui similaridades entre os diversos casos. Todas as Igrejas abordadas nesta pesquisa estão instaladas nas áreas mais pobres do município de Nova Iguaçu, onde as condições de vida são bastante desfavoráveis à população. Ruas com esgoto a céu aberto, precária iluminação e bastante afastadas dos serviços oferecidos no centro urbano constituem uma espécie de cenário padrão onde estas igrejas surgem. Sendo assim, estes locais são marcados pela ausência do poder público, o que os transformam em ambientes propícios para o surgimento de novas formas de sociabilidade onde o "vizinho" tem muito mais a oferecer que os governantes oficialmente instituídos. Neste contexto, as pastoras ocupam um lugar de destaque. Em questões de emergência relacionadas a moradores das adjacências de suas igrejas, é comum que elas sejam solicitadas para prestar auxílio, independente da religião de quem peça a ajuda. Um caso exemplar é o de Pastora Joana $^{8}$. Moradora de um bairro pobre de Nova Iguaçu, no qual criou sua Igreja denominada "Templo Evangélico Pentecostal Emanuel”, ela nos conta em sua entrevista que sua velha caminhonete era constantemente usada por vários de seus vizinhos, ao mesmo tempo em que sua presença era bastante requisitada para apaziguar casos de contenda entre moradores. Dessa forma, podemos sugerir que estas pastoras são colocadas em uma posição peculiar frente aos demais, como se as mesmas

\footnotetext{
${ }^{8}$ Todos os nomes citados nesta comunicação são fictícios.
} 
verdadeiramente tivessem algum tipo especial de autoridade para solucionar questões e conceder ajuda nos momentos de necessidade. Pode-se também concluir que a liderança no âmbito religioso atravessa os muros da igreja e se expande pela comunidade onde vivem estas líderes. Ser uma líder religiosa reconhecida também torna possível ocupar uma posição diferenciada frente aos vizinhos.

\section{4- A liderança carismática exercida pelas novas líderes - diálogo com Lindholm}

Segundo Lindholm, a característica mais pujante da liderança carismática é o fato de que ela se trata de uma fonte de ações baseadas na emoção. Sob esta perspectiva, a energia, a abnegação e fervor coletivos são elementos inerentes á dinâmica de um grupo instituído em torno de uma figura carismática. Assim sendo, a análise mais adequada de um movimento de cunho carismático deve desconsiderar, pelo menos à priori, argumentos racionais que se afastam das mais variadas formas de comprometimento emocional que podem surgir nos relacionamentos dos atores sociais. Aliás, como o próprio Lindholm observa, no Ocidente a idéia de atração carismática constitui uma maneira de falar de certos aspectos emocionais da interação social, seja nos movimentos de massa ou nos acontecimentos da vida social cotidiana. Temos então que,

Em cada nível, do mais individual ao mais abrangente, permanece o conceito de uma ligação compulsiva e inexplicável unindo um grupo de seguidores em veneração conjunta a seu líder, ou unindo o amante ao ser amado, comumente simbolizado pela imagística do carisma (LINDHOM, Ibidem: 13)

Seguindo os apontamentos feitos por Lindholm, podemos perceber que existe a necessidade de melhor apreendermos o significado emocional e psicológico que o envolvimento em um movimento carismático tem para os líderes e seus seguidores. Em se tratando do caso das novas líderes pentecostais femininas de Nova Iguaçu, é possível observarmos que, no âmbito de suas atividades religiosas, há um apelo emocional profundamente marcante que singulariza a relação entre elas e seus seguidores. Durante 
a realização da pesquisa de campo feita nas igrejas selecionadas presenciamos recorrentemente situações nas quais as líderes e seus seguidores demonstravam uma espécie de envolvimento emocional que era intensificado durante as ações rituais efetivadas nos cultos. Especialmente no decorrer das orações de cura e da distribuição das revelações, ficava bastante explícito que o relacionamento entre líderes e liderados alcançava a esfera emocional dos indivíduos envolvidos.

Como fora dito acima, as orações de cura e a distribuição de revelações são os principais atrativos dos cultos promovidos pelas novas líderes. Tendo em vista os anseios daqueles que vão à busca dos resultados prometidos por estas duas ações rituais específicas, podemos, a princípio, considerar que estes indivíduos estariam mais propensos a vivenciarem experiências baseadas no extravasamento de emoções. Acima expomos algumas colocações feitas por Lindholm em seu prefácio á edição brasileira de "Carisma", onde o autor aponta que os movimentos de cunho carismático geralmente se desenvolvem quando os indivíduos atravessam situações de marginalização e adversidades extremas capazes de ameaçar a própria sobrevivência. Uma vez que a pesquisa aqui apresentada está sendo realizada sobre um recorte geográfico que, ao mesmo tempo, é também um recorte sócio-econômico, parece válido sugerirmos que há um perfil geral daqueles que buscam os produtos religiosos oferecidos por estas recémfundadas igrejas. Em primeiro lugar, a ineficácia do sistema público de saúde é um fato que sobressai não apenas em Nova Iguaçu, como também em todo estado do Rio de Janeiro. Consequientemente, esta ineficiência faz com que os indivíduos, sobretudo os oriundos das camadas sociais mais baixas, sejam levados à busca de outras possibilidades de atendimento médico, tais como os oferecidos pelos propalados “centros sociais" mantidos por particulares. Da mesma forma, conforto e promessas de cura oferecidos pela religião também aparecem como uma via bastante procurada por aqueles que desejam a resolução para seus problemas de saúde. Embora corramos o risco de atribuir uma explicação funcionalista ao fenômeno em questão, parece plausível considerarmos que o fato de as igrejas pesquisadas enfatizarem a realização das orações de cura em suas atividades atrai, especialmente, aqueles que sofrem de enfermidades e que não possuem acesso a outras possibilidades de tratamento. Igualmente, as condições nas quais vive grande parte da população de Nova Iguaçu também colaboram para a alta capilaridade que as igrejas pentecostais que distribuem revelações encontram entre os evangélicos. Uma vez que a incerteza permeia a vida daqueles que vivem em situação 
de marginalização e desassistidos pelo poder público, qualquer artifício que acene com uma possibilidade de dias melhores tende a ser bem quisto. E as revelações distribuídas pelas pastoras de bispas entrevistadas podem ser observadas sob esta ótica. A certeza de que o filho largará o vício de drogas, de que há chance de cura para uma doença sem tratamento possível, ou de que há uma iminente oportunidade de emprego preenchem uma espécie de lacuna na vida dos indivíduos que procuram este tipo de produto religioso nas igrejas pesquisadas.

Através da observação do significado que os produtos religiosos oferecidos nas igrejas pesquisadas possuem para aqueles que constituem o séquito das novas líderes podemos expor com mais propriedade a maneira como a esfera emocional dos indivíduos envolvidos é acessada durante os cultos. A fragilização emocional daqueles que buscam orações de cura ou revelações é potencializada pela carga emocional que as novas líderes trazem a tona durante os cultos. Durante a pesquisa de campo realizada nas igrejas pode-se observar que as orações de cura e a distribuição de revelações eram recorrentemente feitas em um clima sobremaneira emotivo. Todos os seguidores mostravam-se propensos a manifestarem suas emoções frente aos demais e, sobretudo, diante de suas líderes. As ações rituais eram realizadas sempre em meio ao choro compulsivo das líderes e seus seguidores. O trecho abaixo, extraído das gravações feitas durante os cultos visitados durante a pesquisa de campo, nos ajuda a ilustrar o quão emotivo é o discurso das líderes:

Meu Deus, papai, meu papai, faça com essa mulher possa ter sua saúde de volta. Eu te peço paizinho, restaura a vida dessa mulher. Ela precisa da saúde dela de volta, ela precisa trabalhar porque eu sei paizinho, a vida dela não está fácil. Cura a perna dela meu pai, em nome de Jesus. (trecho de uma oração de cura feita por pastora Joana)

O trecho seguinte é parte de uma revelação proferida por pastora Linda, e também expressa um conteúdo emocional bastante enfático.

Deus manda um anjo me dizer que tem uma mulher aqui sofrendo com o vício da bebida, que ela tenta parar de beber mais não consegue. Ela até escondeu um monte de garrafas debaixo da cama 
dela e do marido dela. E ela sabe quem é que estou falando. Irmã, Deus manda você vir aqui na frente pra receber a sua vitória.

Após um intervalo de dois minutos uma mulher se levanta em meio aos fiéis e vai em direção ao altar. Chorando copiosamente a pastora continua seu discurso

Irmã, Deus vai curar você. Seu sofrimento é o meu também, porque quando eu era do mundo eu também sofria com a bebida. Mas Deus manda dizer pra você nessa noite que você nunca mais vai colocar uma gota de álcool na boca!

O intercruzamento entre a análise desenvolvida por Lindholm e a sociologia weberiana nos aponta outra importante questão acerca do conteúdo emocional inerente aos movimentos carismáticos. Segundo Weber (1982), os líderes carismáticos típicos (xamãs, epiléticos, demagogos, profetas, piratas e guerreiros furiosos) possuem em comum o fato de serem marcados por uma capacidade única e inata de demonstrar grandes emoções. De acordo com o ponto de vista weberiano, as figuras carismáticas vivem em um estado de consciência alterado, intensificado e fora dos padrões da vida emocional comum com que operamos. Dessa maneira, a expressividade acentuada do carismático seria, para Weber, a grande responsável por atrair os seguidores. Orientado por perspectiva semelhante a de Weber, Lindholm também nos diz que a expressividade emocional do indivíduo carismático atua como uma fonte geradora de magnetismo, da mesma forma que alimenta a sujeição do liderado frente ao seu líder. Ao analisar os perfis de Jim Jones, Hitler e Manson, Lindholm nos indica que todas estas três personalidades compartilhavam de uma capacidade exacerbada de expressar suas emoções para seus respectivos séquitos. Assim sendo, fundamentados nos dados da pesquisa podemos dizer que, semelhantemente aos líderes carismáticos retratados por Lindholm, as novas líderes pentecostais pesquisadas também possuem este traço essencialmente carismático, que é o da expressão exacerbada de suas emoções.

$\mathrm{O}$ envolvimento emocional entre líderes e liderados algumas vezes parecia extrapolar os limites do culto propriamente dito. A veneração dedicada ás líderes, embora fundamentada em elementos essencialmente ligados ao exercício de seus "dons espirituais" durante os cultos, também pôde ser observada nas declarações que os 
indivíduos entrevistados nos deram a respeito do relacionamento que mantêm para além dos muros da igreja. Pastora Margareth nos deu o seguinte depoimento:

Eu realmente me importo com minhas ovelhas, por isso que não gosto quando alguém daqui vai na igreja da irmã ..., porque eu sei que eles sempre voltam de lá com mais problemas do que antes. Quando qualquer um deles precisam de mim eu estou lá, na porta da casa deles pronta pra ajudar (...) Se precisar eu corro esse bairro todo atrás de outras irmã e faço um grupo forte pra ir lá me ajudar a orar pela ovelha que ta sofrendo. Se você tava aqui no último culto você viu o que eu disse (...) Eu disse pra eles: eu me importo com vocês porque eu amo todos vocês, e eu duvido que a irmã ... sinta por vocês o que eu sinto. Eu sempre tive todos vocês como meus filhinhos do coração.

Da mesma forma, os relatos dos seguidores também apontam para a existência de um envolvimento emocional que supera os limites do culto propriamente dito. Ao analisarmos o conteúdo das entrevistas dos membros seguidores foi possível constatarmos que as líderes são recorrentemente citadas em meio a um discurso profundamente emotivo inspirado em sentimentos alimentados não apenas pelos dons espirituais que estas possuem, mas também pelos traços de suas personalidades e pela maneira como se dedicam àqueles que participam de seus círculos de relações. Ana, seguidora do Templo Evangélico Pentecostal Emanuel, nos deu a seguinte declaração sobre sua líder:

Eu andei por muitas igrejas, mas aqui com a irmã Joana eu me senti em casa. Não se sei se é porque ela me lembra muito minha mãe, mas eu criei uma amizade com ela de cara (...) Eu amo a pastora Joana, mas amo também a amiga Joana, porque ela não é só pastora da gente, ela também se importa com a gente como se fosse da família dela.

É importante observarmos que a manifestação do carisma somente pode acontecer quando existe o encontro entre uma personalidade com traços carismáticos e indivíduos "aptos" para ocuparem a posição de seguidores. A atração magnética, apontada por Lindholm como sendo um dos elementos primordiais do carisma, é algo que 
passa a existir somente quando há interação entre aquele que será o líder e aqueles que serão os liderados.

O carisma só aparece na interação com outras pessoas que não o possuem. Em outras palavras, embora o carisma seja pensado como algo intrínseco ao indivíduo, uma pessoa não pode revelar esta qualidade estando isolada. Ela só aparece na interação com aqueles que são por ela afetados. Carisma é, sobretudo, um relacionamento, uma mútua ligação íntima entre líder e o seguidor. Sendo assim, se o carismático tem a capacidade de compelir, o seguidor tem a capacidade de ser compelido (LINDHOLM, Ibidem: 19).

Em função disso, a análise da dinâmica do grupo criado em volta da liderança carismática é indicada por Lindholm como algo extremamente necessário, uma vez que

Compreender o carisma não implica somente o estudo da personalidade carismática e dos atributos que tornam qualquer indivíduo suscetível ao apelo carismático, mas também uma análise da dinâmica do próprio grupo carismático no qual o líder e seus seguidores interagem (LINDHOLM, Ibidem: 20).

Seguindo as orientações de Lindholm, foram entrevistados vários seguidores das novas líderes com o intuito de melhor apreendermos a configuração da liderança exercida por estas mulheres em suas igrejas. Ao observarmos os relatos dos seguidores destas líderes foi possível perceber que suas carências sobressaem como a principal motivação para que estes busquem os produtos religiosos das igrejas pesquisadas. Como fora descrito acima, é bastante comum que indivíduos com sérios problemas de saúde procurem auxílio nestas congregações, e relatos de cura são tão freqüentes que terminam por atuar à maneira de um "cartão de visitas" àqueles que também se encontram enfermos. Igualmente, as revelações também operam no sentido de atender determinadas necessidades dos indivíduos que vão a procura destas igrejas. Assim 
sendo, podemos concluir que a interação entre os líderes e liderados é determinadas por estas singularidades inerentes à dinâmica dos grupos analisados.

\section{Considerações finais}

Expomos acima as principais características que, segundo Charles Lindholm, compõem a liderança carismática. Com base nos apontamentos deste autor foi possível enquadrar a onda de fundação de igrejas pentecostais por mulheres como um fenômeno pautado, sobretudo, no carisma destas novas líderes. O envolvimento emocional suscitado entre estas mulheres e seus seguidores seria o principal indicador de que a liderança exercida por estas pastoras e bispas está baseada na esfera das emoções passíveis de serem acessadas dentro e fora dos cultos que promovem. Contudo, devemos fugir de explicações sintéticas em prol de reconhecermos que, muito provavelmente, outros fatores agem simultaneamente ao carisma destas novas líderes no sentido de viabilizar a fundação de novas igrejas pentecostais por mulheres. Da mesma forma, não devemos descartar a hipótese de que não é um trabalho solo do carisma que possibilita a permanência destas igrejas no cenário religioso pentecostal.

Enfim, podemos sugerir algumas questões sobre o futuro de fenômeno religioso em questão. Segundo Weber, a liderança carismática tende a dar origem a duas outras formas de autoridade: a tradicional ou a racional-legal. Este processo de rotinização do carisma religioso começa com o abandono das praticas mágicas e do seguimento dos profetas e culmina na formação de um quadro administrativo que se limita apenas à transmissão dos ensinamentos religiosos formalizados pela tradição. Seguindo os apontamentos feitos por Weber, somos levados a questionar quais as transformações pelas quais a legitimação da autoridade das novas líderes passará no futuro. Será que o carisma destas mulheres será cristalizado em um quadro burocrático? Ou, haverá a possibilidade do carisma hoje vigente encontrar outras formas de atuação sem necessariamente passar por processos de transformações vinculados a racionalização? São questões que permanecem sem respostas no presente. 


\section{REFERÊNCIAS BIBLIOGRÁFICAS}

BIRMAN, Patrícia. Mediação Feminina e Identidades Pentecostais, Cadernos Pagu, Campinas, UNICAMP nº 6-7, 1996.

FRY, Peter; HOWE, Gary: Duas respostas à aflição: umbanda e pentecostalismo. Debate e Crítica, n 6: 79-94, São Paulo, 1975.

HERVIEU-LÉGER, Daniele. O peregrino e o convertido: a religião em movimento. Petrópolis: Vozes, 2008.

JACOB, César Romero et alli. Religião e Sociedade em Capitais Brasileiras. Rio de Janeiro, Ed. PUC-Rio; São Paulo, Loyola; Brasília, CNBB, 2006./

LINDHOLM, Charles. Carisma: êxtase e perda de identidade na veneração ao líder. Rio de Janeiro: Jorge Zahar Ed., 1993.

MACHADO, Maria das Dores Campos; MARIZ, Cecília. Mulheres e práticas religiosas nas classes populares: uma comparação entre as igrejas pentecostais, as Comunidades Eclesiais de Base e os grupos carismáticos. RBCS, vol. 12, n 3, Junho, 1997. . Pentecostalismo e a Redefinição do Feminino. Religião \& Sociedade, Rio de Janeiro, v. 17, n. 1/2, p. 140-159, 1996.

SANTOS, Maria Goreth. A mulher na hierarquia evangélica: o pastorado feminino. Dissertação de Mestrado. PPCIS - UERJ, 2002

WEBER, Max. Os três tipos puros de dominação legítima (trad. Gabriel Cohn). In: Max Weber: Sociologia. Gabriel Cohn (organizador). São Paulo: Ática, 1982. (Grandes Cientistas Sociais; 13) p.128-141. 
Ensaios de Sociologia. Ed. Guanabara, $5^{\circ}$ edição, Rio de Janeiro, 1982. 